\title{
Measures of Emotion in Interaction for Health Smart Home
}

\author{
M. J. Kim, M. E. Cho, and J. T. Kim
}

\begin{abstract}
Many researchers have worked on the measurement of emotion from the perspectives of their various domains, but there is little research on emotion in interaction in the architecture domain. To develop measures of emotion in interaction associated with spaces, this paper reviews representative studies and techniques adopted for the measurement of emotion in Human-Computer Interaction. Emotional states and emotional response are two important factors to be considered in measuring emotion. In general, emotional states are divided into discrete and dimensional emotion models, whereas emotional responses are organized in terms of experiential, physiological, and behavior response. A critical review would enable the consolidation of knowledge to develop appropriate measures for emotion in interaction design. Through an exhaustive search on contents pages of articles, systematic methods for measuring emotional states and responses were examined, and several problems specific to the measurement of each emotion component were investigated.
\end{abstract}

Index Terms-Emotion, measurements, multi-componential response, experiential response, physiological response, behavior response.

\section{INTRODUCTION}

Human-Computer Interaction (HCI) has become a promising research area. A significant number of researches have been conducted on smart technologies, where a long-running discussion has been taking place within the HCI domain about usability and user experience (UX) issues [1]. HCI researchers are aware of the limitations of the traditional usability framework, which primarily focuses on user performance. To extend the capacity of the framework beyond reflecting HCI's concern with productivity, these researchers began paying attention to the notion of UX, shifting the focus to user affect and emotion [2]-[4]. The traditional usability methodologies have been regarded as ill-suited to the measures of emotion because there are limitations in accounting for and evaluating emotions [1], [5]. In this paper, we discuss affective and emotional aspects of interaction in smart technologies. The paper provides an overview of current research theories and studies into the measurement of emotion in HCI to develop measures of emotion in interaction associated with spaces. It is expected that the consolidation of knowledge related to the measurement of emotions would be provided to develop appropriate measures for emotion in interaction design.

Manuscript received June 16, 2014; revised July 28, 2014. This work was supported in part by the National Research Foundation of Korea (NRF) grant funded by the Korea government (MSIP) (No. 2008-0061908).

The authors are with the Department of Housing and Interior Design, Kyung Hee University, Seoul 130-701, Republic of Korea (e-mail: mijeongkim@khu.ac.kr,mecho@khu.ac.kr, jtkim@khu.ac.kr).

\section{DEFINING AND MEASURING EMOTIONS}

Various definitions of emotion exist in different domains such as psychology, neuroscience and design; thus, it is not easy to reach consensus on the definition of emotion. The various domains focus on different phenomena of emotions [6]. We are interested in the definition of emotion proposed by psychologists, in which emotion is regarded as a process of changes in different components rather than a homogeneous state [1]. The different states such as anger, disgust or happiness can be categorized into emotions by combining different levels of these main components. The most controversial issue in research on the emotions concerns how many emotions exist and what they are [7]. When we try to identify patterns of emotional expression, we find they are highly varied [8]. In general, the emotions can be largely categorized from two perspectives: discrete and dimensional. The two perspectives differ in how they conceptualize and describe emotional states [9], [10].

The discrete emotion theories were inspired by Darwin [11]. Researchers proposed a set of basic emotions from which emotion experiences are constructed [12]-[18]. From the discrete emotions perspective, each emotion corresponds to unique components in experience, physiology, and behavior [19], [20]. For example, Ekman's model identifies six basic emotions: happiness, sadness, fear, surprise, anger, and disgust [21], whereas Izard proposed eleven basic emotions [18]: interest, joy, surprise, sadness, anger, disgust, contempt, fear, shame, shyness, and guilt. The discrete emotions are grouped according to their eliciting conditions: consequences of events, actions of agents, or aspects of objects [22].

The dimensional model, which specifies emotions according to their position in an n-dimensional space, was proposed by Wundt [23]. There are a few fundamental dimensions that organize emotional responses in dimensional models [10]. For example, feelings can be varied by their position on three dimensions: pleasantness-unpleasantness, rest-activation, and relaxation-attention [23]. The most common dimensions are valence, arousal, and approach-avoidance [24], [25]. The valence dimension is a continuum of states of pleasure and states of displeasure, whereas the arousal dimension is a continuum of states of low arousal and states of high arousal. Approach motivation is characterized by tendencies to approach stimuli, whereas avoidance motivation is characterized by tendencies to avoid stimuli [10], [22].

Heidt [26] argued that it is possible to reconcile dimensional and discrete perspectives to some extent. Each discrete emotion can represent a combination of several 
dimensions by offering a hierarchy that groups similar emotions into families, each family being subdivided into small subsets [26]. For example, anger could be characterized by negative valence, high arousal, and approach motivation; whereas, fear could be characterized by negative valence, high arousal, and avoidance motivation [10].

The ambiguity of the definition of emotion makes it more difficult to measure [8]. Emotion is an important factor in designing smart systems; thus, it should be evaluated appropriately by relevant methods and tools. Usability is the question of how well people can use the functionality of the system [2]. The notion of usability does not include feelings such as delight or excitement [27]. In general, usability testing focuses on efficiency, speed, and error rates, i.e. not linked to human experience. It has a very limited view of emotion, concerning the pleasant-unpleasant dimension. As a number of researchers become aware of the limitations of usability, activities have increased to better understand UX including emotional, affective, experiential, hedonic, and aesthetic variables [28]-[30]. With a focus on UX, more suitable methods for emotion measurement have been discussed and proposed.

\section{EMOTION MEASUREMENT}

The development of instruments to measure emotions has been one of the most important research areas. Acknowledging the important role of emotions, it has been popular in the fields of psychology and sociology, and subsequently in the fields of consumer and marketing, and more recently computer science [31]. To develop measures of emotion in interaction associated with spaces, we begin by reviewing representative studies and techniques adopted for the measurement of emotion in Human-Computer Interaction.

\section{A. Multi-Componential Response}

People respond emotionally to stimuli or situations in various ways, not just one fixed way; thus, there is no one standard method for the measurement of emotions. A convergent measurement assessing all component changes can provide a comprehensive measure of an emotion [8]. This view that considers all facets of emotional response is useful to organize the measurement techniques available to HCI. The multiple components of emotion proposed by representative researchers are as shown in table 1.

Scherer[8] categorized emotional response into five types: the continuous changes in appraisal processes at all levels of central nervous system processing; the response patterns generated in the neuroendocrine, autonomic, and somatic nervous systems; the motivational changes produced by the appraisal results; the patterns of facial and vocal expression as well as body movements; and the nature of the subjectively experienced feeling state that reflects all of these component changes. Desmet [31] treated emotion as a multifaceted phenomenon consisting of the following components: behavioral reactions, expressive reactions, physiological reactions, and subjective feelings. There seems to be no empirical solution to the debate on which components are sufficient or necessary to define emotions. Laurans [6] included the following elements under the heading of "emotion": give rise to affective experiences such as feelings of arousal, pleasure/displeasure; generate cognitive processes such as emotionally relevant perceptual effects, appraisals, labeling processes; activate widespread physiological adjustments to the arousing conditions; lead to behavior that is often, but not always, expressive, goal-directed, and adaptive. The definition of emotion contains the breadth of the phenomenon, reflecting the complexity of emotions as responses including many of these elements. Mauss [10] divided emotional response into emotional experience, physiology, and behavior, whereas Lang [7] categorized it into affective evaluation, facial expressiveness, visceral reactivity, and behavioral responses that maintain or terminate stimulation.

\begin{tabular}{|c|c|c|c|c|}
\hline Scherer [8] & Desmet[31] & $\begin{array}{l}\text { Laurans et } \\
\text { al.[6] }\end{array}$ & $\begin{array}{l}\text { Mauss et } \\
\text { al.[10] }\end{array}$ & $\begin{array}{l}\text { Lang et } \\
\text { al.[32] }\end{array}$ \\
\hline $\begin{array}{l}\text { Appraisal of } \\
\text { the eliciting } \\
\text { event }\end{array}$ & $\begin{array}{l}\text { Behavioral } \\
\text { reactions }\end{array}$ & $\begin{array}{l}\text { Affective } \\
\text { experiences }\end{array}$ & $\begin{array}{l}\text { Subjective } \\
\text { experience }\end{array}$ & $\begin{array}{l}\text { Affective } \\
\text { evaluation }\end{array}$ \\
\hline $\begin{array}{l}\text { Physiological } \\
\text { symptoms }\end{array}$ & $\begin{array}{l}\text { Expressive } \\
\text { reactions }\end{array}$ & $\begin{array}{l}\text { Cognitive } \\
\text { processes }\end{array}$ & $\begin{array}{l}\text { Peripheral } \\
\text { physiology }\end{array}$ & $\begin{array}{l}\text { Facial } \\
\text { expressiveness }\end{array}$ \\
\hline $\begin{array}{l}\text { Action } \\
\text { tendencies }\end{array}$ & $\begin{array}{l}\text { Physiological } \\
\text { reactions }\end{array}$ & $\begin{array}{l}\text { Physiological } \\
\text { adjustment }\end{array}$ & Behavior & $\begin{array}{l}\text { Visceral } \\
\text { reactivity }\end{array}$ \\
\hline $\begin{array}{l}\text { Motor } \\
\text { expression }\end{array}$ & $\begin{array}{l}\text { Subjective } \\
\text { feelings }\end{array}$ & Behavior & & $\begin{array}{l}\text { Behavioral } \\
\text { responses }\end{array}$ \\
\hline Feelings & & & & \\
\hline
\end{tabular}

Based on the result of the critical reviews of the definition of emotion and multi-componential responses, we developed three main components of emotional response in $\mathrm{HCI}$ : experiential response, physiology response, and behavior response.

\section{B. Assessing Emotional Responses}

Many studies, with varying approaches and relevancy to the measurement of emotions, have been conducted to develop reliable methods of assessing emotion. These can be divided according to the components of the emotional response as follows.

\section{1) Experiential response}

The individual can be aware of the emotional state and describe it with a rich emotional lexicon to communicate his/her response to certain stimuli [33]. The experiential response can be divided into verbal and non-verbal instruments. Verbal self-report instruments assess the subjective feeling component of emotions, where each emotion involves a specific basic feeling [34]. The most popular instruments require respondents to report their emotions using a set of rating scales or verbal protocols. The rating scales can be assembled to represent any set of emotions as well as mixed emotions [31]. Verbal reports of affects have a great richness and subtlety of discrimination, with a lot of emotionally descriptive words [7]. The 
self-assessment manikin (SAM, see [35]) is a non-verbal instrument. Using schematic manikins to represent the different feelings states, it provides a quick assessment of valence (how positive or negative a person feels), arousal (a calm-excited scale) and dominance (feeling in control of the situation)[36]. A non-verbal instrument is proposed by the evolutionary foundation of emotion that has a simpler, two-factor motivational organization [7]. Several questionnaires based on categorised emotions have been used in design-oriented research to describe users' experiences [36]. The Geneva Emotion Wheel [8] is a verbal self-report instrument that includes 20 emotion families, whereas PrEmo [31] is a non-verbal measurement tool comprising 10 to 14 animations representing different emotions. Through the use of these tools, we can ask potential users to report their feelings about existing products to inform the design process [36], [37].

\section{2) Physiological response}

Physiological response to an emotional event has been a popular area of emotion research, both empirical and theoretical [36, 38]. The physiological changes include alterations of heartbeat and breathing rates, body temperature and skin conductivity [33]. Thus, blood pressure responses, skin responses, brain waves, heart responses, etc. are measured by appropriate instruments [31]. There are empirical researches that describe the correlation between different physiological systems and emotion [36], [39].

The autonomic nervous system (ANS), a general-purpose physiological system responsible for modulating peripheral functions, displays physiological manifestations that can be measured with measurement techniques [10]. The most commonly used assessments are based on electrodermal or cardiovascular responses. Electrodermal response is quantified in terms of skin conductance level (SCL) or short-duration skin conductance responses (SCRs). The most commonly used cardiovascular measures include heart rate (HR), blood pressure (BP), total peripheral resistance (TPR), cardiac output (CO), pre-ejection period (PEP), and heart rate variability (HRV) [10]. Many researchers have proposed that the physiological correlates of discrete emotions are likely to be found in the brain, and have taken up this challenge using EEG and neuroimaging methods [20], [40]-[42]. EEG measures contrast activation in large regions of the brain, often anterior versus posterior, in combination with the distinction between left-sided and right-sided hemispheric activation. Neuroimaging studies, using fMRI (functional magnetic resonance imaging) or PET (positron emission tomography) technologies, can locate activation in far more specific brain regions than EEG [10].

Several researchers in affective computing have developed ANS instruments, such as IBM's emotion mouse [43] and wearable sensors designed by the Affective Computing Group at MIT [44]. With these instruments, computers can gather multiple physiological signals while a user is experiencing an emotion, and learn what pattern is most indicative of an emotion [31]. These techniques have some practical advantages, e.g. they yield continuous measures without the users' attention in an objective way. However, there are difficulties in using psychophysiological techniques.
Firstly, specific expertise and complex equipment are necessary. Further, the sensors - usually adhesive electrodes attached to the skin with cables running to the recording device, reduce the freedom of movement of the participants [36], [45]. The most difficult part of psychophysiological measurement is the interpretation. Emotion is not the only process to affect visceral activity, thus it is hard to identify unambiguous associations between specific emotions and patterns of bodily activation. It is thus extremely difficult to use psychophysiological recording on its own to provide an assessment of users' emotions while interacting with a system. Therefore, much of the research into these techniques supplements them with self-report data, focusing on the physiological activation itself [36].

\section{3) Behavior response}

Each emotion is associated with a particular pattern of expression [10], [46]. For example, anger is accompanied by a fixed stare, contracted eyebrows, compressed lips, brisk movements, and a raised voice [31]. Emotional states can be linked to action dispositions [25], [47].

TABLE II: ResPonse SyStem, MEASURES AND EMOTIONAL STATES

\begin{tabular}{|c|c|c|}
\hline $\begin{array}{l}\text { Response } \\
\text { system }\end{array}$ & Measures (Evaluation method) & $\begin{array}{l}\text { Emotional states } \\
\text { (Sensitivity) }\end{array}$ \\
\hline \multirow[t]{5}{*}{$\begin{array}{l}\text { Experiential } \\
\text { Response }\end{array}$} & $\begin{array}{l}\text { Verbal } \\
\text { self-report instruments with the } \\
\text { use of a set of rating scales or } \\
\text { verbal protocols }\end{array}$ & $\begin{array}{l}\text { represent any set of } \\
\text { emotions, and can be } \\
\text { used to measure } \\
\text { mixed emotions }\end{array}$ \\
\hline & Non-verbal & \\
\hline & $\begin{array}{l}\text { Self-assessment } \\
\text { Manikin-SAM }\end{array}$ & $\begin{array}{l}\text { valence, arousal and } \\
\text { dominance }\end{array}$ \\
\hline & - Geneva Emotions Wheel & 20 emotion families \\
\hline & $\begin{array}{l}\text { Product Emotion Measuring } \\
\text { Instrument }\end{array}$ & \\
\hline \multirow{7}{*}{$\begin{array}{l}\text { Physiological } \\
\text { Response }\end{array}$} & autonomic nervous system & \\
\hline & - electrodermal system: SCL & $6-8$ basic emotions \\
\hline & $\begin{array}{l}\text { cardiovascular system: HR, } \\
\text { BP }\end{array}$ & valence and arousal \\
\hline & affect-modulated startle & valence and arousal \\
\hline & central physiology(CNS) & approach and \\
\hline & - $\quad$ EEG & avoidance \\
\hline & - fMRI, PET & \\
\hline \multirow{5}{*}{$\begin{array}{l}\text { Behavior } \\
\text { Response }\end{array}$} & Motor expression & \\
\hline & $\begin{array}{l}\text { Facial expression: FACS, } \\
\text { MAX, FEAT, EMG }\end{array}$ & $\begin{array}{l}6-8 \text { basic emotions } \\
\text { valence }\end{array}$ \\
\hline & $\begin{array}{l}\text { Vocal expression: pitch, } \\
\text { pitch changes, intensity of } \\
\text { color, speaking rate, voice } \\
\text { quality, and articulation }\end{array}$ & arousal \\
\hline & Action tendency & approach and \\
\hline & observer ratings & avoidance \\
\hline
\end{tabular}

In this research, we regard the former as a motor expression and the latter as an emotional state according to action tendencies as shown in Table II.

There are two major motor expression instruments: measuring facial and measuring vocal expressions [31]. Examples of theories that link expression features to distinct emotions are the Facial Action Coding System (FACS) [48], 
and the Maximally Discriminative Facial Moving Coding System (MAX) [49]. Generally, visible expressions captured on stills or short video sequences are analyzed. An example of an analysis tool is the Facial Expression Analysis Tool (FEAT) [50]. A related approach is facial electromyography. Electromyography (EMG) is recorded with electrodes placed on the skin, where the recording of the electrical signal is generated by action potentials in the motor neurons controlling muscles. Specific electrode placements (loci) are used to record the activity of different facial muscles [36]. Similar to the facial expression instruments, vocal instruments measure the effects of emotion in multiple vocal cues, based on theories that link patterns of vocal cues to emotions [31], [51].

The HCI literature also provides examples of the use of this technique [6], [36]. Tendencies to approach or avoid its object are a fundamental aspect of emotion. Researches in psychology and neuroscience suggest that these behavioral tendencies are engaged even when perceiving or remembering emotions. Evaluation of a stimulus also seems to be reliably associated with a behavioral tendency to approach pleasurable stimuli and to avoid negatively valenced stimuli [36], [52], [53]. As with other psychophysiological measures, the complexity and relative obtrusiveness of the technique and the inconsistency of the findings might be an obstacle to its use as a routine tool for user experience research [36].

\section{CONCLUSION AND Discussion}

Researchers in HCI have worked on usability studies for a considerable amount of time, and recently began to pay attention to UX because they became aware of the limitations of the traditional usability framework that emphasizes productivity. Usability does not account for and evaluate the range of emotions that can be linked to human experience. Although some studies on user satisfaction have been conducted, they are limited to the satisfaction associated with efficiency and error rates. They have been regarded as ill-suited to measure emotion.

We are interested in affective and emotional aspects of interaction in smart technologies, and investigated related works that deal with the measuring of emotion to develop more relevant tools for measuring emotion in interaction associated with spaces. The paper provides an overview of current research theories and studies relevant to the measurement of emotion in HCI. It is expected that the consolidated knowledge related to the measurement of emotions would be provided to assist in developing appropriate measures for emotion in interaction design.

There are, in general, two perspectives in emotional states: the discrete emotion model and dimensional emotion model. However, we found that reconciling the dimensional and discrete perspectives to some extent seems to be desirable. As Heidt argued [26], each discrete emotion can represent a combination of several dimensions by offering a hierarchy that groups similar emotions into families, each family being subdivided into small subsets. Regarding emotional response, we organized it into three components based on the notion of the multi-componential model: experiential response, physiological response, behavior response. We examined whether emotional responses are associated with specific patterns of experience, physiology, and behavior. For measuring experiential response, verbal instruments have the strength to provide a great richness and subtlety of discrimination. Through the physiological response, more objective data can be collected, but there is difficulty in interpreting the collected data. Further, research into the physical response does not uncover unambiguous associations between specific emotions and patterns of bodily activation. Using psychophysiological recording on its own seems to be problematic in providing an assessment of users' emotions while interacting with a product. Although technological complexity occurs in adopting the behavior response, the HCI community has used the behavior response for measuring the users' emotional responses to a media player, portable audio player and computer games.

In this paper, we review representative studies and techniques adopted for the measurement of emotion, and highlight research issues on UX to be addressed for measuring emotion in interaction with smart environments. It was found that there is no single standard method for the measure of emotion in existing research that accounts for and evaluates emotional states and responses. Rather, various methods are proposed to measure different emotional states and responses, which are not strongly related to one another. Emotions are constituted by multiple, situationally and individually variable processes. We plan to study further to identify which method can be reliable and validated for each situation in measuring emotions associated with HCI.

\section{ACKNOWLEDGMENT}

This work was supported by the National Research Foundation of Korea (NRF) grant funded by the Korea government (MSIP). (No. 2008-0061908)

\section{REFERENCES}

[1] K. R. Scherer, ed. Emotion, the Psychological Structure. International Encyclopedia of the Social and Behavioral Scciences, ed. N.J. Smelesr and P.B. Baltes, Pergamon: Oxford, 2001.

[2] C. Dormann, Affective Experiences in the Home: Measuring Emotion, in HOIT 2003, Irvine, California, 2003.

[3] R. W. Picard and J. Klein, "Computers that recognise and respond to user emotion: theoretical and practical implications," Interacting with Computers, vol. 14, pp. 141-169, 2002.

[4] E. L. C. Law, V. Roto, M. Hassenzahl, A. P. O. S. Vermeeren, and J. Kort, "Understanding, scoping and defining user experience: a survey approach," in Proc. the SIGCHI Conference on Human Factors in Computing Systems, ACM: Boston, MA, USA. pp. 719-728, 2009.

[5] P. Thomas and R. D. Macredie, "Introduction to the new usability," ACM Trans. Comput.-Hum. Interact, vol. 9, no. 2, pp. 69-73, 2002.

[6] G. Laurans, P. M. A. Desmet, and P. Hekkert, "Assessing emotion in human-product interaction: an overview of available methods and a new approach," International Journal of Product Development, vol. 16, no. 3, pp. 225-242, 2012

[7] P. J. Lang, M. M. Bradley, and B. N. Cuthbert, "Emotion, motivation, and anxiety: brain mechanisms and psychophysiology," Biological psychiatry, vol. 44, no. 12, pp. 1248-1263, 1998.

[8] K. R. Scherer, "What are emotions? and how can they be measured?," Social Science Information, vol. 44, no. 4, pp. 695-729, 2005.

[9] L. F. Barrett, "Solving the emotion paradox: categorization and the experience of emotion," Pers Soc Psychol Rev, vol. 10, no. 1, pp. 20-46, 2006.

[10] I. B. Mauss and M. D. Robinson, "Measures of emotion: a review," Cognition and Emotion, vol. 23, no. 2, pp. 209-237, 2009. 
[11] C. Darwin, The Expression of the Emotions in Man and Animals, 1965, The University of Chicago Press: Chicago, 1965.

[12] P. Ekman, W. V. Friesen, M. O'Sullivan et al., "Universals and cultural differences in the judgments of facial expressions of emotion," J. Pers Soc Psychol, vol. 53, no. 4, pp. 712-717, 1987.

[13] P. Ekman, "An argement for basic emotions," Cognition and Emotion, vol. 6, pp. 3-4, pp. 169-200, 1992.

[14] C. E. Izard, The Face of Emotion, 1971, Appleton-Century-Crofts: New York, 1971

[15] C. E. Izard, "Basic emotions, relations among emotions, and emotion-cognition relations," Psychol Rev, vol. 99, no. 3, pp. 561-565, 1992.

[16] S. S. Tomkins, ed. Affect Imagery Consciousness, 1962, Springer: New York, 1962.

[17] R. Plutchik, The Emotions: Facts, Theories and a New Model, 1962, Random House: New York, 1962.

[18] C. E. Izard, Human Emotions, Plenum Press: New York, 1977.

[19] P. Ekman, Basic Emotions, Handbool of Cognition and Emotion, Wiley, New York, pp. 45-60, 1999.

[20] J. Panksepp, "Neurologizing the psychology of affects: how appraisal-based constructivism and basic emotion theory can coexist," Perspectives on Psychological Science, vol. 2, no. 3, pp. 281-296, 2007.

[21] P. Ekman, "An Argument for basic emotions," Cognition and Emotion, vol. 6, pp. 169-200, 1992.

[22] M. Wong, Emotion Assessment in Evaluation of Affective Interfaces, 2006, University of Waterloo. 2006.

[23] W. M. Wundt, Grundzuge Der Physiologischen Psychologie. Fundamentals of Physiological Psychology, 1902.

[24] J. A. Russell and L. F. Barrett, "Core affect, prototypical emotional episodes, and other things called," Journal of Personality and Social Psychology, vol. 76, no. 5, pp. 805-819,1999.

[25] P. J. Lang, M. M. Braadley, and B. N. Cuthbert, Motivated Attention: Affect, Activation, and Action, Attention and Orienting: Sensory and Motivational Processes, Lawrence Erlbarm Associates: Mahwah, NJ, pp. 97-135, 1997.

[26] J. Haidt and D. Keltner, "Culture and facial expression: open-ended methods find more expressions and a gradient of recognition," Cognition and Emotion, vol. 13, no. 3, pp. 225-266, 1999.

[27] P. W. Jordan, "Future trends and product design," in Proc. the Human Factors and Ergonomics Society Annual Meeting, vol. 44, no. 32, pp. 61-64. 2000.

[28] E. Law, V. Roto, A. P. O. S. Vermeeren, J. Kort, and M. Hassenzahl, Towards a Shared Definition of User Experience, in CHI '08 Extended Abstracts on Human Factors in Computing Systems, ACM: Florence, Italy, pp. 2395-2398, 2008.

[29] E. L. C. Law, A. P. O. S. Vermeeren, M. Hassenzahl, and M. Blythe, Towards a Ux Manifesto, in Proceedings of the 21st British HCI Group Annual Conference on People and Computers: British Computer Society: University of Lancaster, United Kingdom, pp. 205-206. 2007.

[30] M. Hassenzahl and N. Tractinsky, "User Experience - a Research Agenda," Behavior \& Information Technology, vol. 25, no. 2, pp. 91-97. 2006.

[31] P. Desmet, Measuring Emotion: Development and Application of an Instrument to Measure Emotional Responses to Products, in Funology, A. B. Mark et al., Editors, 2004, Kluwer Academic Publishers, pp. 111-123. 2004.

[32] P. J. Lang, M. K. Greenwald, M. M. Bradley, and A. O. Hamm, "Looking at pictures: affective, facial, visceral, and behavioral reactions," Psychophysiology, vol. 30, no. 3, pp. 261-273, 1993.

[33] D. G. Caicedo and M. V. Beuzekom, An Assessment of Existing Tools for the Measurement of Emotions and Their Application in Consumer Products Research, 2006, Delft University of Technology, 2006.

[34] [E. B. Titchener, Lectures on the Elementary Psychology of Feeling and Attention, 1908, Macmillan: New York, 1908.

[35] M. M. Bradley and P. J. Lang, "Measuring emotion: the self-assessment manikin and the semantic differential," Behavior Therapy and Experimental Psychiatry, vol. 25, no. 1, pp. 49-59, 1994.

[36] G. Laurans, "Assessing emotion in human-product interaction: an overview of available methods and a new approach," International Journal of Product Development, vol. 16, no. 3, pp. 225-242, 2012.

[37] P. Desmet and E. Dijkhuis, "A wheelchair can be fun: a case of emotion-driven design," in Proc. the 2003 International Conference on Designing Pleasurable Products and Interfaces, ACM: Pittsburgh, PA, USA, pp. 22-27, 2003.

[38] A. Damasio, Descartes' Error: Emotion, Reaason, and the Human Brain, 1994, Putnam Publishing. 1994.
[39] J. T. Cacioppo, D. J. Klein, G. G. Berntson, and E. Hatfield, The Psychophysiology of Emotion, pp. 119-142, 1993.

[40] W. B. Cannon, "Again the james-lange and the thalamic theories of emotion," Psychological Review, vol. 38, pp. 281-295,1931.

[41] C. Izard, "Levels of emotion and levels of consciousness," Behavioral and Brain Sciences, vol. 30, no. 1, pp. 96-98, 2007.

[42] P. Bard, "A diencephalic mechanism for the expression of rage with special reference to the sympathetic nervous system," American Journal of Physiology, vol. 84, pp. 490-515, 1928.

[43] W. S. Ark, D. C. Dryer, and D. J. Lu, "The emotion mouse," in Proc. HCI International (the 8th International Conference on Human-Computer Interaction) on Human-Computer Interaction: Ergonomics and User Interfaces, pp. 818-823, 1999.

[44] R. W. Picard, "Toward computers that recognize and respond to user emotion," IBM Syst. J., vol. 39, pp. 3-4, pp. 705-719, 2000.

[45] J. Anttonen and V. Surakka, "Emotions and heart rate while sitting on a chair," in Proc. the SIGCHI Conference on Human Factors in Computing Systems, USA. pp. 491-499, 2005.

[46] P. Ekman, All Emotions Are Basic, The Nature of Emotion: Fundamental Questions, Oxford University Press: New York, 1994.

[47] N. H. Frijda, The Emotions, Cambridge University Press: Cambridge, UK. 1986.

[48] P. Ekman and W. V. Friesen, Facial Action Coding System, A Technique for the Measurement of Facial Movement, Consulting Psychologists Press, CA, 1978.

[49] C. E. Izard, The Maximally Discriminative Facial Movement Coding System, Instructional Recourses Centre, University of Delaware: Newark, 1979.

[50] S. Kaiser and T. Wehrle, Facial Expressions as Indicator of Appraisal Processes, Oxford University Press: Oxford, 2001.

[51] T. Johnstone and K. R. Scherer, eVocal Communication of Emotion, The Guilford Press: New York, 2001.

[52] M. Chen and J. A. Bargh, "Consequences of automatic evaluation: immediate behavioral predispositions to approach or avoid the stimulus," Personality and Social Psychology Bulletin, vol. 25, no. 2, pp. 215-224, 1999.

[53] S. Bamford and R. Ward, "Predispositions to approach and avoid are contextually sensitive and goal dependent," Emotion, vol. 8, no. 2, pp. 174-183, 2008.

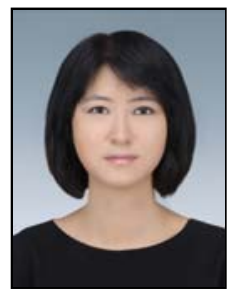

Mi Jeong Kim received her Ph.D (2007) in the key centre of design computing and cognition form the University of Sydney, Sydney, Australia. She completed a bachelor and a master of housing and interior design at Yonsei University, Seoul, Korea. During the bachelor course, she was trained as a designer through design studio courses, and for the Master course, she undertook research in the area of housing.

She as an associate professor of Housing and Interior Design at Kyung Hee University, Seoul, Korea. She worked as a postdoc fellowship in the Department of Engineering Research Support Organization in UC Berkeley before joining Kyung Hee University. The paper "The impact of tangible user interfaces on designers' spatial cognition" was selected as one of the ten most cited papers in 'Human-Computer Interaction'. Her current research interests include Design Studies and Human-Computer Interaction.

Prof. Kim obtained the architecture engineer license and joined the Korean Society of Interior Architects/Designers. She is an associate editor for the 'Journal of The Korean Institute of Interior Design,' and on the editorial board for 'Visualization in Engineering'.

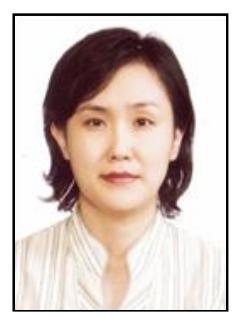

Myung Eun Cho received her bachelor, master and Ph.D in the Department of Housing and Interior at the University of Yonsei, Seoul.

She as a research professor of Housing and Interior Design at Kyung Hee University, Seoul, Korea. She worked as a product developer and researcher at LG Design Institute and worked as a postdoc fellowship and a lecture professor at various Universities. Current research interests include design and evaluation of new interaction techniques, empirical studies and smart homes in the architecture domain. 


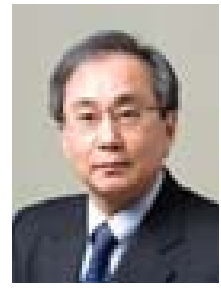

Jeong Tai Kim is a Kyung Hee Distinguished Fellow at Kyung Hee University and is a fellow of the Korea Academy of Science and Technology (KAST). In September of 2008, He founded the center for sustainable healthy buildings $(\mathrm{CSHeB})$ with the award of engineering research center (ERC) from Korea Government. As the director of the $\mathrm{CSHeB}$, he has tried to establish an outstanding R\&D center with global competitiveness by providing on-site research facilities, formulating synergistic interconnection with interdisciplinary researchers, and promoting collaboration and cooperation with various industries, government departments, and international universities. He also plays a key role in promoting sustainable healthy building technologies academically by hosting international symposiums, seminars, and workshops.

$\mathrm{He}$ acted as the president of the Acoustical Society of Korea (2005), the Korea Institute of Ecological Architecture and Environment (2007-2008), and currently acts as the President of the Korea Society of Lighting and Visual Environment and the vice-president of the International Society of the Built Environment. 